\title{
Implementasi Digitalisasi Laporan Finansial, Pemasaran, dan Perpustakaan pada Komunitas Gubug Baca Cahaya Negeri di Kabupaten Rembang
}

\author{
Riskin Hidayat ${ }^{1}$, A. Aviv Mahmudi ${ }^{2}$ \\ 1,2 STIE YPPI Rembang, Rembang, Indonesia
}

\begin{abstract}
ABSTRAK
Program pengabdian kepada masyarakat ini dilakukan pada Komunitas Gubug Baca Cahaya Negeri (GBCN) Kabupaten Rembang. Komunitas GBCN bergerak di bidang perpustakaan dan juga memiliki warung, menjual produk-produk anggotanya yang dinamakan GBCN Store. Permasalahan yang dihadapi yaitu terbatasnya pengetahuan dan akses pada literatur digital; pengelolaan usaha belum menggunakan manajemen usaha secara modern serta minat berwirausaha belum besar; kemasan produk sangat sederhana yang dipasarkan hanya di lingkungan desa dengan model pemasaran secara konvensional; dan belum melakukan pencatatan transaksi keuangan baik secara manual maupun digital. Untuk mengatasi masalah tersebut, tim melaksanakan beberapa program kegiatan, yaitu melakukan pelatihan digitalisasi laporan finansial, pemasaran dan perpustakaan dan pendampingan program kegiatan. Hasil luaran dari program pengabdian ini adalah: Komunitas GBCN telah memiliki catatan finansial digital dengan aplikasi catatan keuangan dan excel; pemasaran online di aplikasi WhatApps, marketplace Shopee dan website GBCN; memiliki literatur digital berupa e-book dan sudah diupload pada http://www.gbcn.or.id/; sealer, timbangan digital dan kemasan produk yang menarik.
\end{abstract}

Kata kunci: digitalisasi; laporan finansial; pemasaran; perpustakaan; komunitas GBCN.

\begin{abstract}
This community service program is carried out at the Rembang Regency Light Reading Hut Community (GBCN). The GBCN community is engaged in library literacy and also has a shop to sell products of its members called the GBCN Store. The problems faced are limited knowledge and access to digital literature; business management has not used modern business management and interest in entrepreneurship has not been great; very simple product packaging which is marketed only in the village environment with conventional marketing models; and have not recorded financial transactions either manually or digitally. To overcome this problem, the team has implemented several program activities, namely: conducting training on digitizing financial reports, marketing and libraries, and assisting program activities. The outputs of this service program are: The GBCN community already has digital financial records with financial records and excel applications; online marketing on the WhatApps application, Shopee marketplace, and the GBCN website; has digital literature in the form of an e-book and has been uploaded on http://www.gbcn.or.id/; sealers, digital scales and attractive product packaging.
\end{abstract}

Keywords: digitalization; financial reporting; marketing; libraries; GBCN community. 


\section{PENDAHULUAN}

Buku adalah jendela dunia. Ungkapan tersebut bermakna bahwa dengan membuka jendela yaitu buku, diharapkan bisa membuka wawasan dan pengetahuan yang lebih luas bagi orang yang membacanya tentang segala sesuatu yang ada di dunia. Aktivitas membaca bisa dilakukan oleh semua orang dengan latar belakang yang beragam dan semua umur, dari anakanak sampai orang tua. Buku dapat memberikan informasi dan pengetahuan tentang berbagai hal, baik informasi sosial, ekonomi, budaya, politik, agama, teknologi dan ilmu pengetahuan lainnya yang berkaitan dengan kehidupan di dunia ini.

Namun ironisnya, kebiasaan membaca masyarakat Indonesia sampai saat ini masih sangat rendah. Hal tersebut sesuai dengan data dari UNESCO pada tahun 2016, dari 61 negara yang disurvei, Indonesia berada pada peringkat 60 (UNESCO, 2019). Hal tersebut juga diperkuat data dari Pusat Penelitian Kebijakan Pendidikan dan Kebudayaan Balitbang Kemendikbud (2019) tentang Indeks Aktivitas Literasi Membaca (Alibaca) yang diukur dengan empat dimensi, yaitu dimensi kecakapan, akses, alternatif dan budaya menunjukkan aktivitas literasi membaca di Indonesia pada dimensi kecakapan sebesar 75,92\%, dimensi akses sebesar 23,09, dimensi alternatif sebesar $40,49 \%$ dan dimensi budaya sebesar 28,50\%. Dari data tersebut menunjukkan bahwa terdapat korelasi yang positif antara akses dengan budaya (kebiasaan), artinya ketika akses untuk membaca yang dimiliki oleh masyarakat sangat kecil, maka budaya atau kebiasaan membaca membaca juga sangat rendah.

Bila dilihat data dari Pusat Penelitian Kebijakan Pendidikan dan Kebudayaan Balitbang Kemendikbud (2019) tentang peringkat Indeks Alibaca seluruh provinsi yang ada di Indonesia sebagaimana Gambar 1 di bawah, Jawa Tengah berada pada peringkat ke 25 dari 34 provinsi. Sangat ironis juga Jawa Tengah yang berada di Pulau Jawa, Indeks Alibaca-nya berada pada posisi 25 atau 10 dari bawah. 
Gambar 1. Peringkat Indeks Alibaca Provinsi di Indonesia

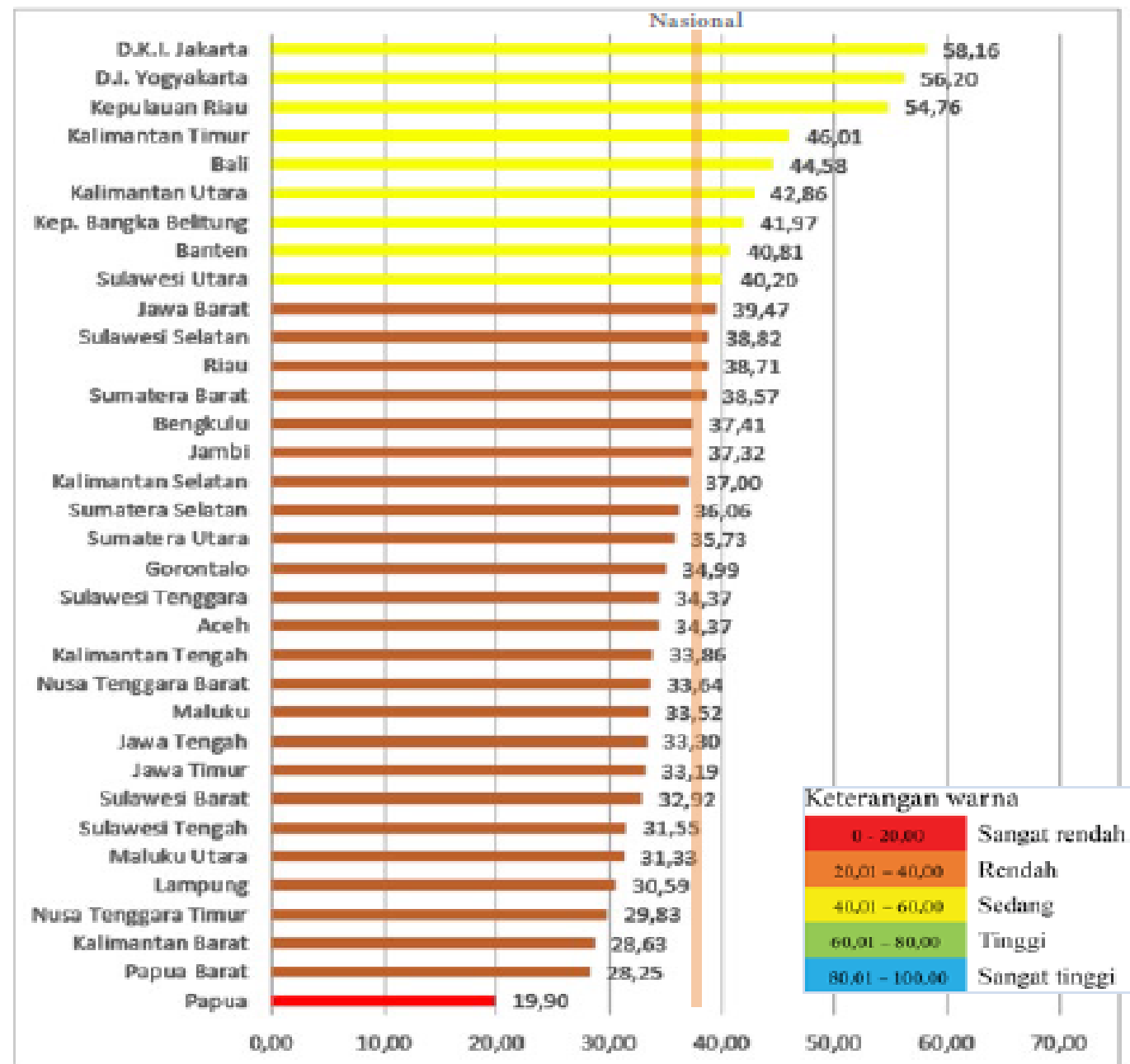

Sumber: Pusat Penelitian Kebijakan Pendidikan dan Kebudayaan Balitbang Kemendikbud (2019)

Melihat kondisi literasi membaca di Indonesia, khususnya di provinsi Jawa Tengah terlebih di Kabupaten Rembang yang sangat memprihatinkan, beberapa anak muda yang ada di Desa Sendangmulyo Kecamatan Kragan tergerak untuk mendirikan komunitas membaca yang dinamakan "Gubug Baca Cahaya Negeri". Desa Sendangmulyo berbatasan dengan sebelah utara Desa Sendang, sebelah timur berbatasan dengan Desa Sendangwaru, sebelah barat berbatasan dengan Desa Tanjungsari Kecamatan Kragan, sedangkan di sebelah selatan berbatasan dengan Desa Bogorejo Kecamatan Sedan. Jumlah penduduk Desa Sendangmulyo tahun 2018 sebanyak 1.804 jiwa (laki-laki sebanyak 877 jiwa dan perempuan sebanyak 927 jiwa). Jumlah sekolah TK di Desa Sendangmulyo sebanyak satu buah dengan jumlah 65 anak dan SD sebanyak satu sekolah dengan jumlah siswa 136 anak. Untuk sekolah tingkat SLTP dan SLTA tidak ada (BPS Kabupaten Rembang, 2019). Hal tersebut menunjukkan fasilitas/akses masyarakat Desa Sendangmulyo untuk membaca sangat minim sekali.

Para pemuda yang tergabung dalam Gubug Baca Cahaya Negeri selain memiliki tempat di Desa Sendangmulyo Kecamatan Kragan, juga berkeliling ke desa-desa sekitar dan setiap minggu membuka lapak membaca buku di Kragan dan Sedan. Namun literasi atau referensi 
yang selama ini disediakan di Gubug Baca Cahaya Negeri masih berupa buku atau majalah secara fisik dengan jumlah masih terbatas dan belum menyediakan buku/majalah/jurnal digital. Padahal saat ini banyak sekali ebook, ejournal, elibrary yang bisa diakses lewat internet. Berdasar hasil survei tim pengabdian, hal tersebut disebabkan karena minimnya pengetahuan untuk mengakses ke link yang menyediakan buku/jurnal/majalah secara gratis. Gambar 2 adalah kondisi literasi yang ada di Gubug Baca Cahaya Negeri

Gambar 2. Kondisi Literasi di Gubug Baca Cahaya Negeri

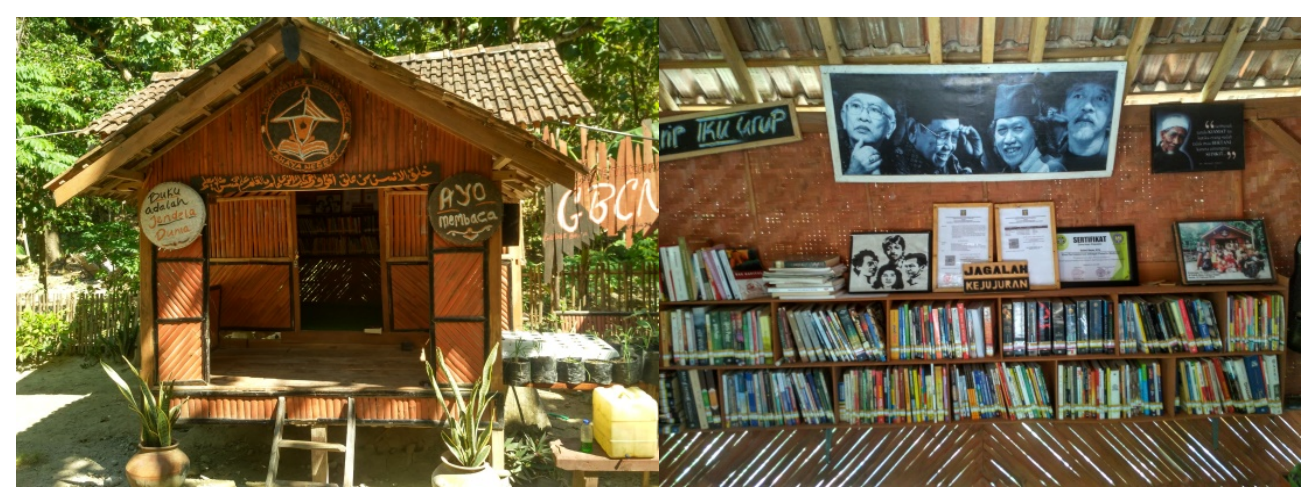

Untuk mendukung dan memotivasi para pengelola Gubug Baca Cahaya Negeri agar tetap semangat dalam mengurus perpustakaan, pengelola juga membuat produk untuk dijual, seperti: madu, keripik singkong dan kerajinan kaligrafi. Hasil survei tim pengabdian menemukan, produk yang dijual, terutama kripik masih dikemas dengan apa adanya, dengan kata lain kemasannya kurang bagus serta pemasaran hanya di lingkungan desa dan sekitarnya secara konvensional. Selain itu dalam pengelolaan usahanya, Gubug Baca Cahaya Negeri belum melakukan pencatatan transaksi keuangan, baik secara manual maupun digital. Salah satu hasil produksi anggota komunitas Gubug Baca Cahaya Negeri dapat dilihat di Gambar 3.

Gambar 3. Hasil Produksi Gubug Baca Cahaya Negeri

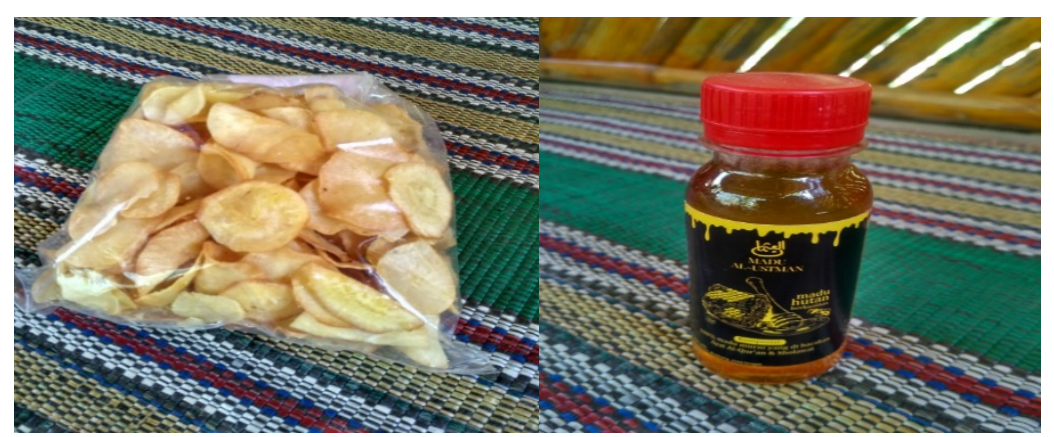

Dari uraian di atas menunjukkan adanya beberapa permasalahan yang dihadapi oleh komunitas Gubug Baca Cahaya Negeri, untuk itu pada program pengabdian masyarakat ini diharapkan bisa membantu menyelesaikan permasalahan yang ada pada mitra. Tim pengabdian STIE YPPI Rembang akan memberikan solusi penyelesaian masalah yang dihadapi oleh mitra terutama dalam hal digitalisasi manajemen keuangan, pemasaran, packaging produk dan perpustakaan. 


\section{METODE PELAKSANAAN}

Metode pelaksanaan yang digunakan untuk menyelesaiakan persoalan mitra adalah: (1) melakukan pelatihan dalam mengakses literatur secara digital dan pelatihan dan manajemen usaha khususnya dalam produksi, pemasaran dan keuangan baik secara manual maupun digital; (2) memfasilitasi pengadaan sealer dan kemasan produk agar produk yang dijual menarik minat konsumen untuk membeli; (3) melakukan pendampingan, baik pada literasi membaca maupun pada usaha yang dijalankan.

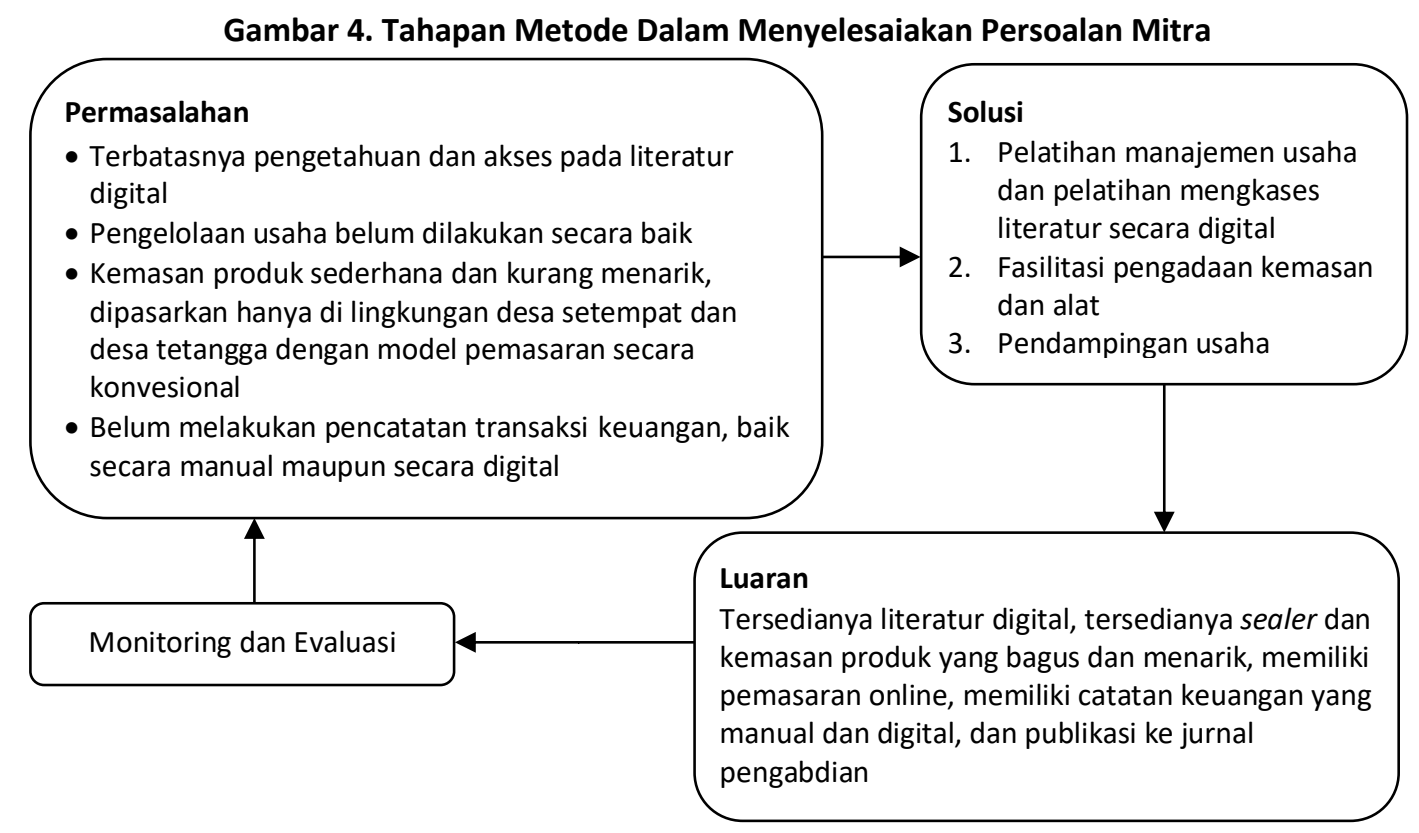

Adapun prosedur kerja dalam program pengabdian kepada masyarakat ini yaitu:

Persiapan. Pada persiapan tim melakukan survei pendahuluan ke daerah mitra. Survei dilakukan untuk mengetahui permasalahan mitra dan solusi bersama yang nanti akan dilaksanakan.

Pelaksanaan. Setelah disepakati permasalahan dan solusinya, maka dilakukan pelatihan dalam mengakses literatur secara digital dan pelatihan manajemen usaha yang meliputi: produksi khususnya packaging produk, pemasaran dan keuangan. Selain itu memfasilitasi pengadaan sealer dan kemasan produk.

Evaluasi. Evaluasi kegiatan perlu dilakukan agar pelaksanaan program pengabdian kepada masyarakat ini bisa diketahui tingkat ketercapaiannya dan manfaat yang diperoleh mitra. Rencana evaluasi pelaksanaan program dilakukan dengan cara mengobservasi langsung di lapangan dengan melihat perkembangan mitra, prestasi yang dicapai terkait dengan pelayanan kepada masyarakat dalam mengakses literatur, perkembangan omset, kondisi keuangan dan jangkauan pasar. 


\section{HASIL DAN PEMBAHASAN}

Kegiatan yang telah dilaksanakan oleh tim pengabdian pada Komunitas Gubug Baca Cahaya Negeri yaitu melaksanakan Pelatihan Digitalisasi Perpustakaan, dan Finansial pada tanggal 26 - 27 September 2020 bertempat di Gubug Baca Cahaya Negeri. Pelatihan diikuti oleh 10 orang anggota komunitas Gubug Baca Cahaya Negeri (GBCN). Materi pada hari pertama tentang pemasaran digital (online), yang dimaksudkan untuk membuka wawasan dan pengetahuan dari anggota komunitas GBCN pentingnya pemasaran online saat ini, baik lewat marketplace, sosial media, maupun website. Hal tersebut dilaksanakan karena selama ini anggota komunitas GBCN menjual produknya secara konvensional. Sehingga dengan adanya pemasaran pelatihan ini bisa merubah paradigm anggota komunitas. Produk-produk yang dihasilkan oleh anggota komunitas ditampung di GBCN Store. GBCN Store sebagai unit bisnis komunitas $\mathrm{GBCN}$ yang menampung hasil-hasil produksi dari para anggotanya dan hasil dari penjualan produk sebagian di masukkan ke kas GBCN.

Awal terbentuknya komunitas GBCN karena kepedulian para anggota komunitas terhadap literasi membaca. Namun dalam perkembangannya anggota komunitas harus berpikir agar perpustakaan yang dikelola tidak berhenti, maka untuk memberdayakan perpustakaan atau literasi membaca masyarakat, anggota komunitas yang terdiri dari beragam latar belakang mulai berpikir untuk mengkombinasikannya dengan berwirausaha. Dari beberapa anggota komunitas memiliki kreativitas dan usaha sendiri-sendiri, seperti kerajinan dari kayu, kaligrafi, kripik telo, gantungan kunci, kerajinan tas, madu dan lainnya. Pelaksanaan pelatihan digitalisasi pemasaran dapat dilihat pada Gambar 5.

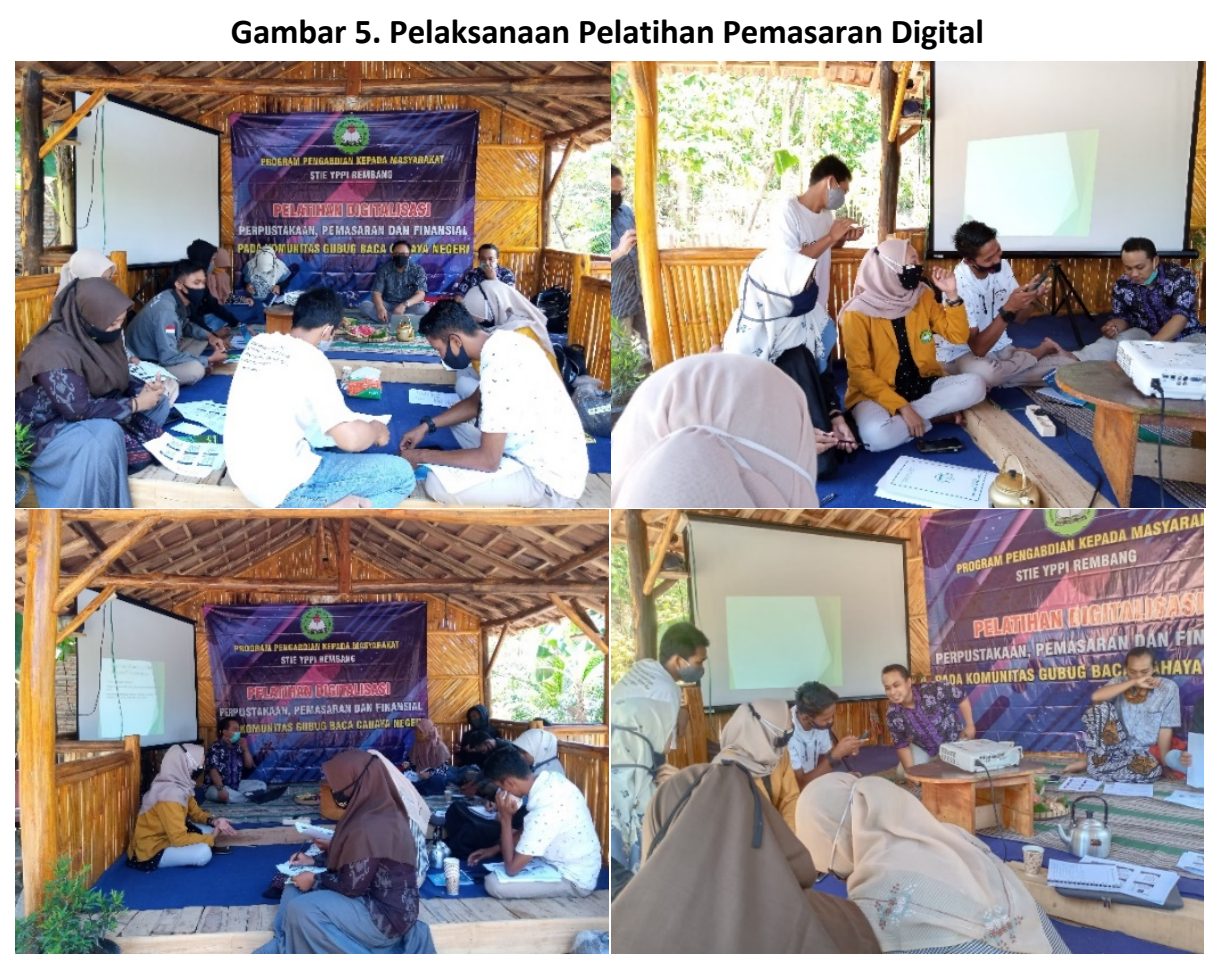


Menurut Kotler dan Amstrong (2018) pemasaran adalah kegiatan menganalisis, mengorgansasi, merecanakan dan mengawasi sumber daya, kebijaksanaan, serta kegiatan yang berkaitan dengan para pelanggan perusahaan dengan tujuan untuk memuaskan kebutuhan dan keinginan kelompok pelanggan yang terpilih untuk memperoleh laba. Dalam melaukan pemasaran, maka diperlukan suatu proses, menurut Abdullah dan Tantri (2013: 4952) proses pemasaran terdiri dari analisis pasar, meneliti dan memilih pasar sasaran, merancang strategi pemasaran, merancang program pemasaran dan mengorganisasi, melaksanakan serta mengawasi usaha pemasaran.

Lebih lanjut menurut Kotler dan Amstrong (2018) bila perusahaan ingin berhasil dalam melakukan pemasaran, maka harus berpegang pada konsep pemasaran, yaitu untuk mencapai tujuan organsasi tergantung pada pengetahuan akan kebutuhan dan keinginan target pasar dan memberikan kepuasan yang diinginkan dengan lebih baik daripada pesaing. Jadi, yang terpenting agar organisasi atau UKM bisa menjual produk sesuai kebutuhan, keinginan serta mendapatkan keuntungan adalah fokus pada nilai pelanggan. Filosofis dari konsep pemasaran adalah "merasakan dan merespon" yang berpusat pada pelanggan. Menurut konsep pemasaran pekerjaan yang harus dilakukan bukanlah menemukan pelanggan yang tepat bagi produk yang dibuat, tetapi menemukan produk yang tepat bagi pelanggan.

Dalam konsep pemasaran yang penting juga adalah melakukan komunikasi pemasaran. Komunikasi pemasaran yang komprehensif tidak terlepas dari baruran promosi, yaitu: periklanan (advertising), penjualan personal (personal selling), penjualan promosi (promotional selling), hubungan masyarakat (public relaition) dan pemasaran langsung (direct marketing). Terdapat satu faktor yang masuk dalam bauran promosi, yaitu pemasaran digital (digital marketing). Untuk kelima faktor bauran promosi lainnya, masing-masing dan secara bersama-sama menunjang terciptanya suatu komunikasi pemasaran yang efektif (Prasetya \& Nurmahdi, 2018).

Pada era revolusi industri 4.0 saat ini, ditambah dengan adanya pandemic Covid-19, maka program pemasaran secara digital menjadi suatu keniscayaan jika perusahaan atau UMKM ingin berkembang dan maju. Pemasaran online sangat cocok untuk bisnis yang baru dirintis karena hemat biaya, tidak harus mengadakan tempat untuk memajang produk, dapat dikendalikan sendiri tanpa harus merekrut karyawan, waktu atau jam kerja yang tidak tterbatas, serta memiliki jangkauan pasar yang luas. Hal tersebut karena pemasaran online didukung oleh keberadaan website atau media social (Facebook, Instagram, WhatApp, Youtube dan lainnya). Hal tersebut sesuai dengan data dari Kominfo (2017) bahwa di Indonesia pengguna internetnya sangat besar yaitu 132 juta pengguna internet aktif dan pengguna media sosial berjumlah 106 juta. Dari 106 juta pengguna media sosial tersebut, pengguna Youtube sebesar 49\%, Facebook sebanyak 48\%, Instagram sebanyak 39\%, Twitter sebanyak 38\%, WhatsApp sebanyak 38\% dan Google sebesar 38\% (Mahardika \& Aji, 2018). Dilihat dari domisilinya, $78,5 \%$ dari total seluruh pengguna internet di Indonesia tinggal di 
wilayah Indonesia bagian Barat. Gambar 6 di bawah ini adalah pemasaran online yang sudah dilakukan oleh komunitas GBCN.

Gambar 6. Pemasaran Digital di WhatsApp dan Shopee
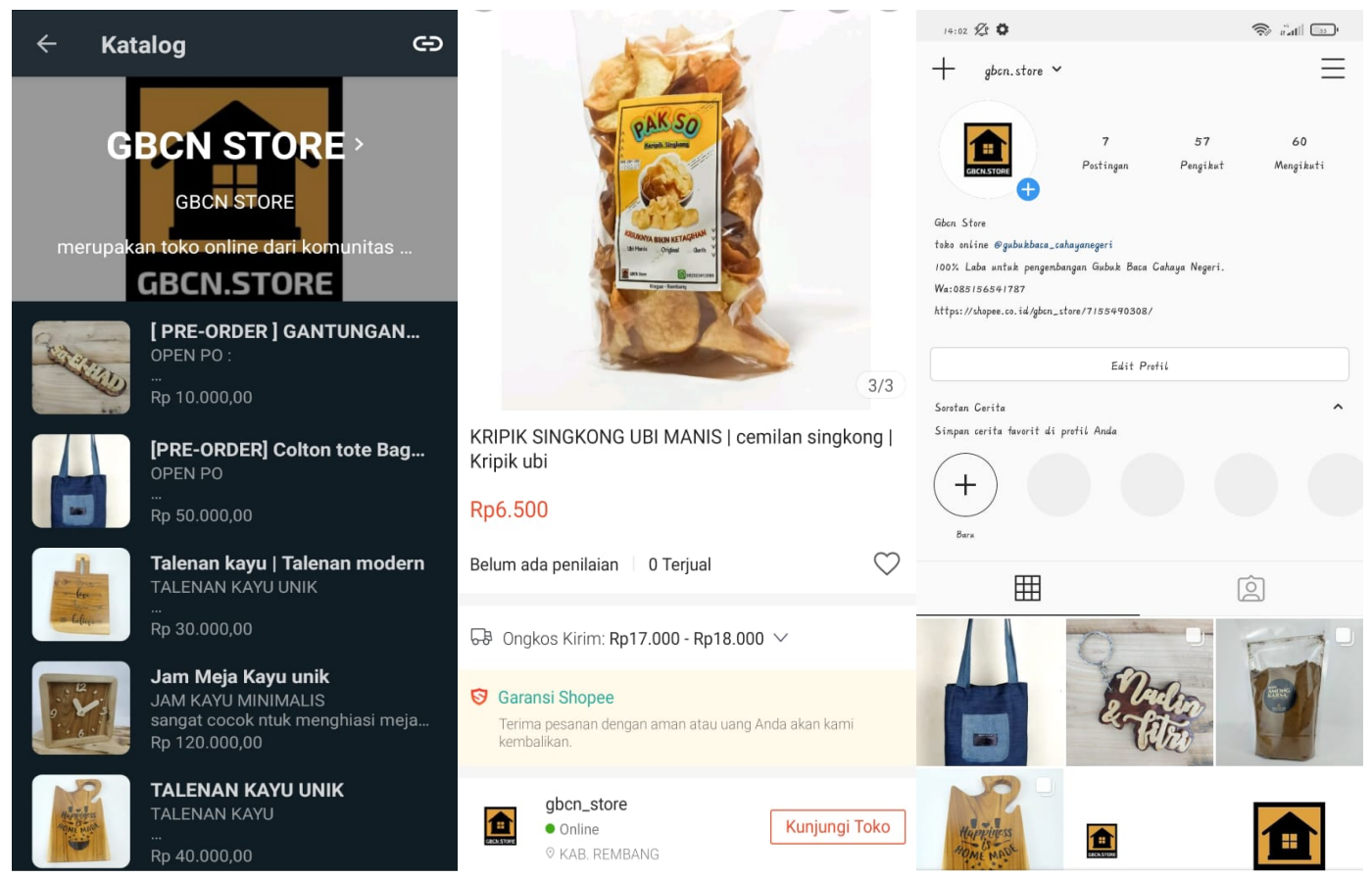

Materi pelatihan yang kedua adalah digitalisasi finansial. Pelatihan digitalisasi finansial diberikan kepada komunitas GBCN karena selama ini GBCN belum memiliki pencacatan keuangan, diharapkan dengan pencatatan secara digital lebih memudahkan GBCN dalam pencatatan finansialnya, karena pencatatan menggunakan smartphone dan bisa diekspor dalam bentuk excel. Pelaksanaan pelatihan finansial digital bisa dilihat pada Gambar 7.

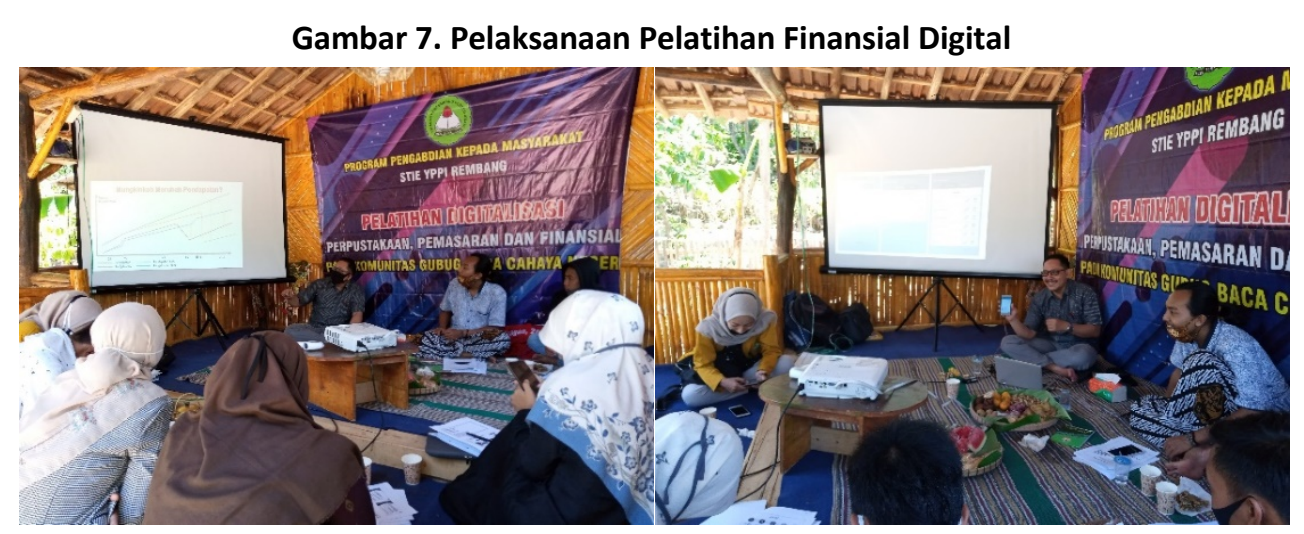

Perkembangan digital yang begitu cepatnya terutama, berdampak pada pencatatan keuangan, baik itu untuk pribadi maupun untuk pencatatan usaha dengan menggunakan aplikasi yang ada di smartphone. Aplikasi pencatatan keuangan yang bisa diunduh secara gratis di play store bisa dimanfaatkan oleh semua orang untuk menggunakannya. Pada pelatihan laporan keuangan digital, tim memberikan materi penggunaan aplikasi "catatan 
keuangan" yang mudah untuk diimplementasikan dan bisa diekspor ke bentuk excel. Sehingga komunitas GBCN bisa menggunakan dengan mudah tanpa harus memiliki laptop atau komputer, transaksi bisa dilakukan sewaktu-waktu dan akan terekam setiap transaksi yang dilakukan. Laporan keuangan secara digital sangat diperlukan oleh komunitas GBCN karena terdiri dari banyak anggota, sehingga perlu ada catatan keuangan agar jelas dan transparan. Hasil dari pelaksanaan pelatihan pencatatan laporan finansial dan pendampingan program pengabdian dari tim dapat dilihat pada Gambar 8.

\section{Gambar 8. Pencatatan Keuangan dengan Aplikasi Catatan Keuangan}

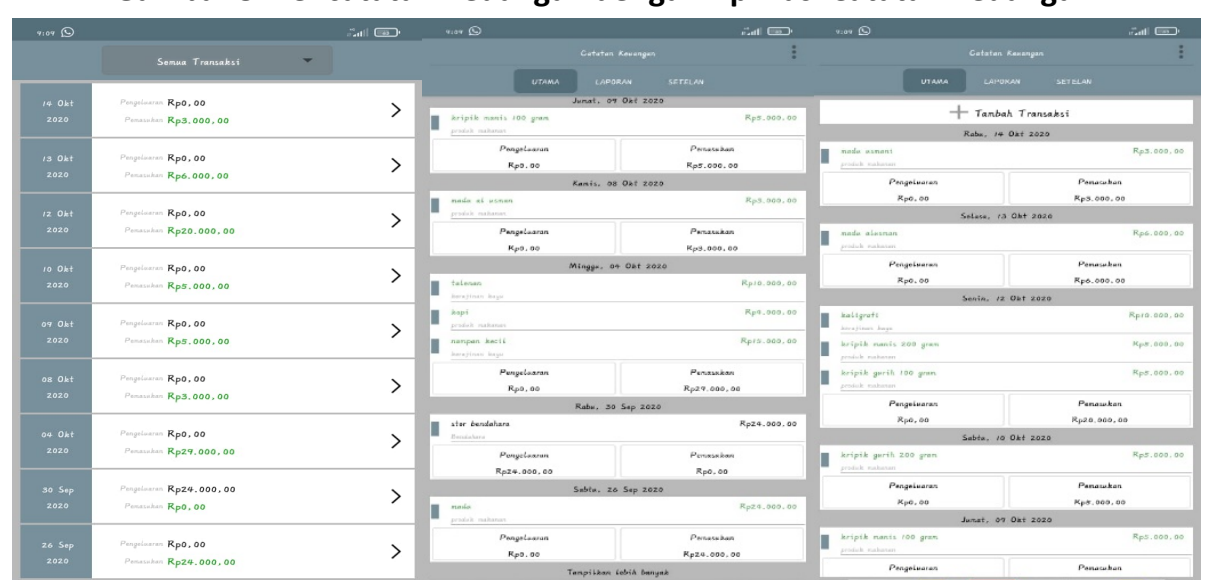

Pelatihan dilanjutkan pada hari kedua, Minggu 27 September 2020 dengan materi digital perpustakaan sekaligus memantapkan materi hari pertama. Perpustakaan digital yang dimaksudkan adalah literasi membaca berupa e-book. Tim pengabdian telah menyerahkan sejumlah e-book kepada komunitas GBCN dengan harapan bisa diakses oleh masyarakat secara luas. Beberrapa e-book yang telah disampaikan oleh tim pengabdian sudah di upload di web komunitas GBCN dengan alamat http://www.gbcn.or.id/ sebagaimana dapat dilihat pada Gambar 9.

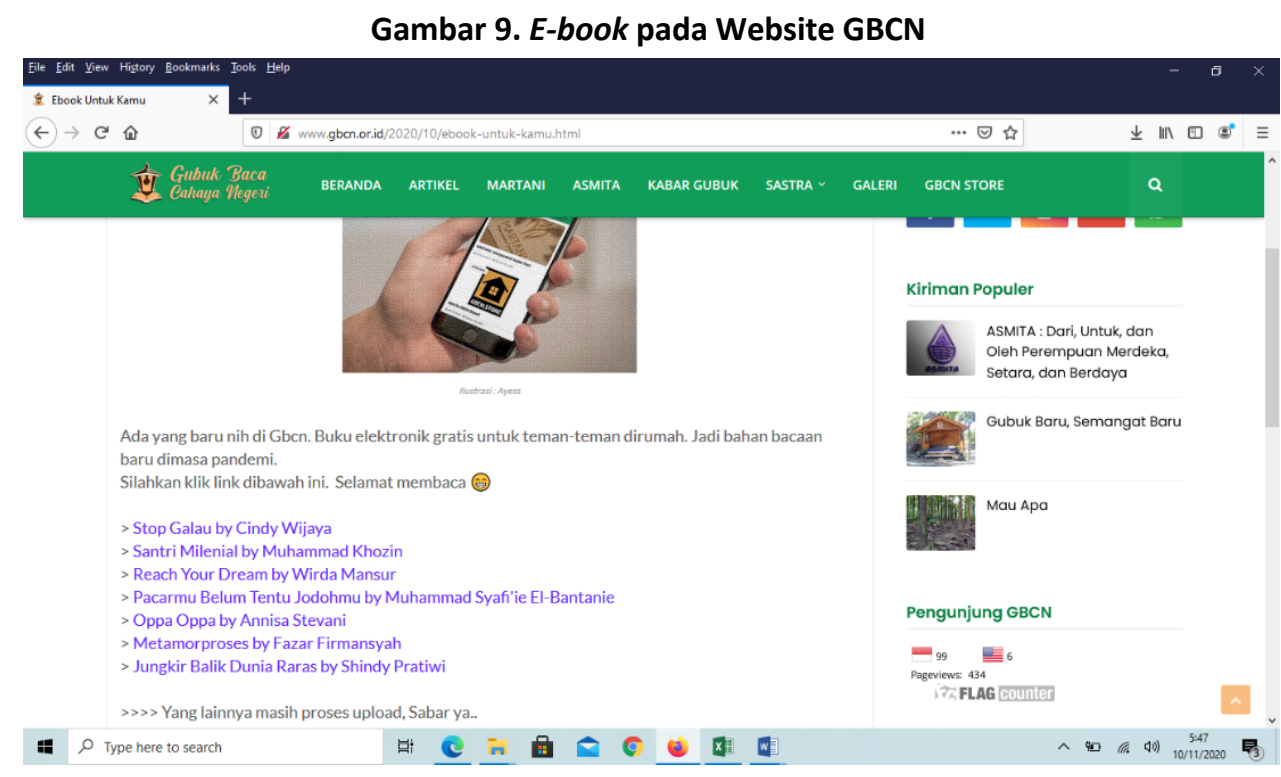


Setelah melakukan pelatihan, agar program bisa berjalan dengan baik dan berkesinambungan, maka tim juga melakukan pendampingan kepada komunitas GBCN. Pendampingan dilakukan untuk mengontrol sampai sejauh mana program dilakukan dan menyerahkan peralatan sealer dan timbangan digital untuk produk kripik telo. Kegiatan pendampingan dan penyerahan alat bisa dilihat pada Gambar 10.

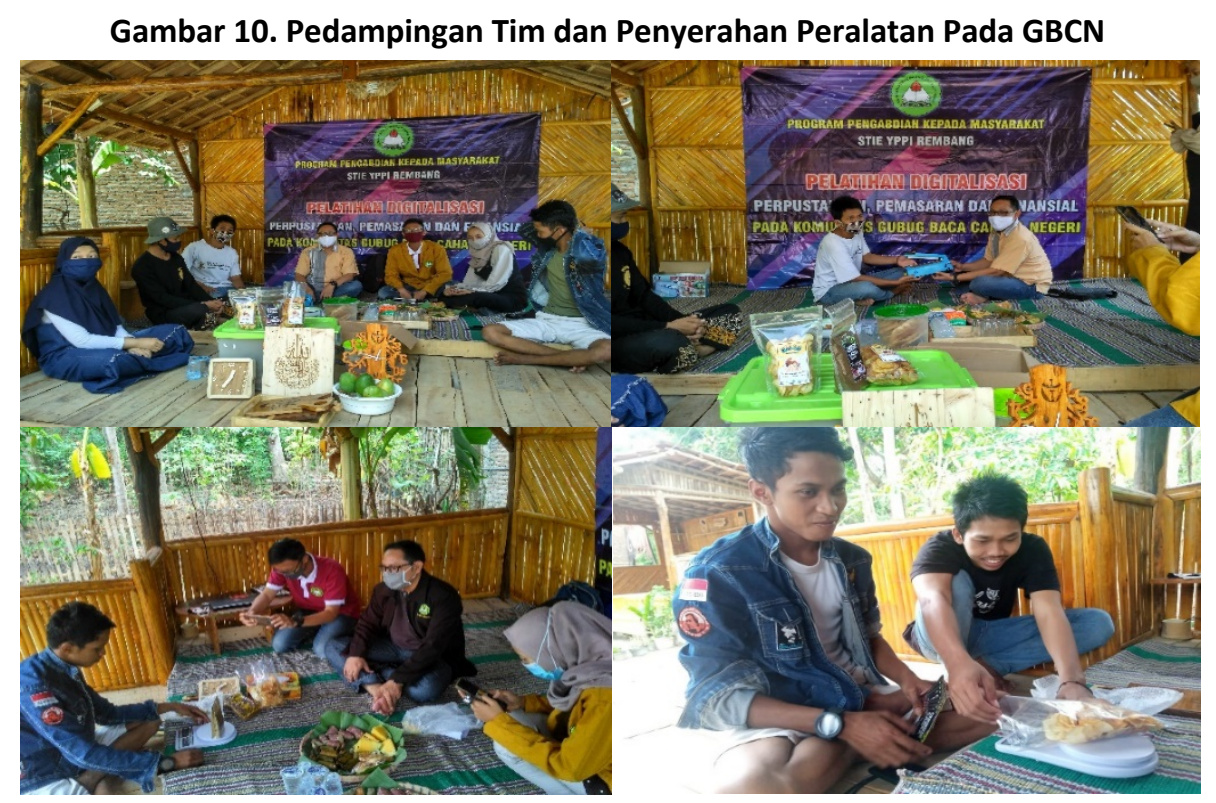

Luaran produk yang dihasilkan oleh Komunitas GBCN dari pelaksanaan program tim pengabdian STIE YPPI Rembang bisa dilihat pada Gambar 11.

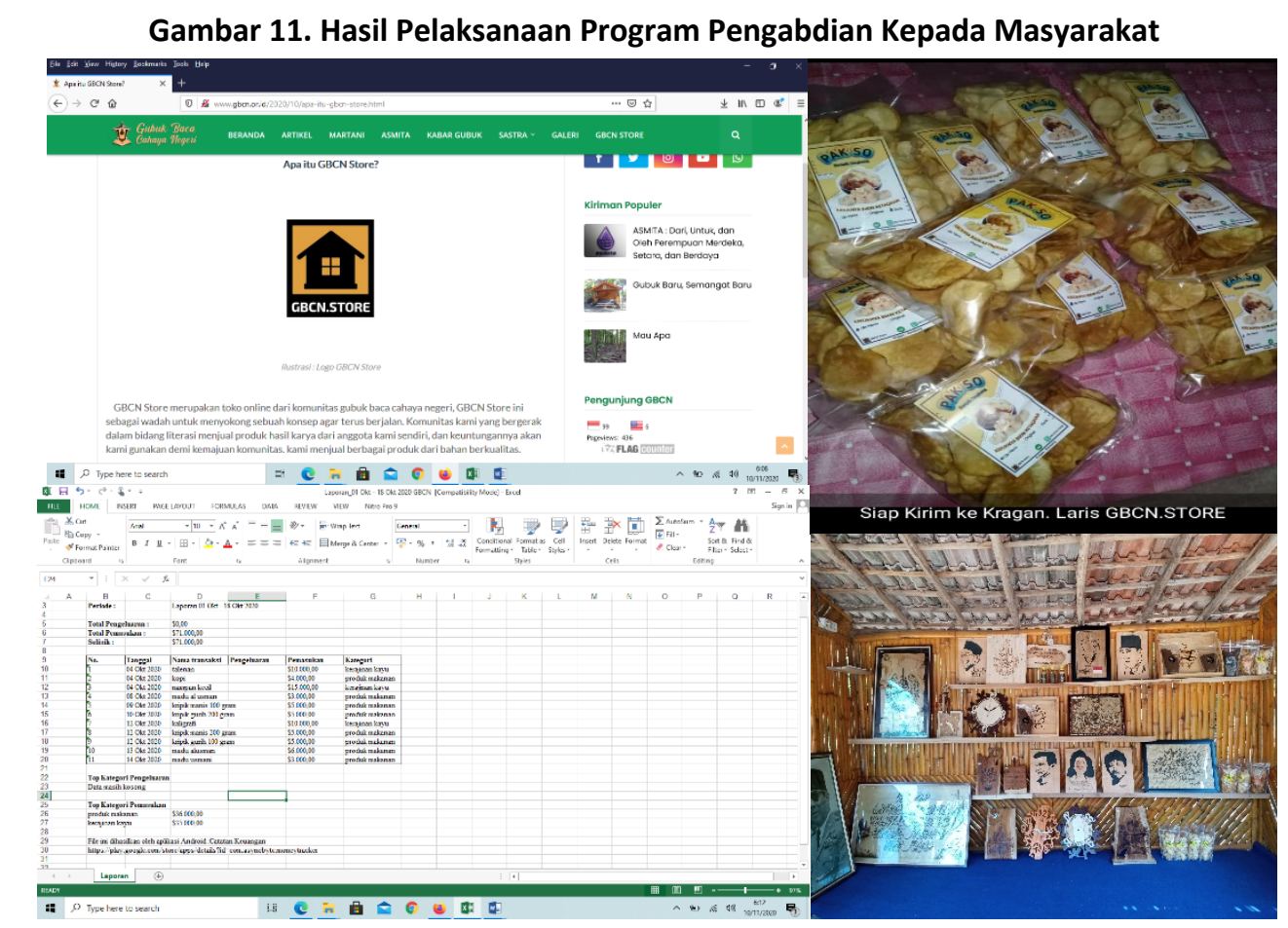




\section{SIMPULAN}

Dari hasil pelaksanaan program pengabdian yang dilakukan oleh tim pengabdian dapat disimpulkan bahwa tim telah menyelesaikan permasalahan yang dihadapi oleh Komunitas Gubug Baca Cahaya Negeri (GBCN) dengan menghasilkan: (1) laporan keuangan digital; (2) pemasaran digital (online) melalui website, sosial media dengan WhatApp dan market place menggunakan shopee; (3) kemasan produk kripik yang menarik; dan (4) e-book yang sudah di upload di website GBCN dengan alamat http://www.gbcn.or.id/. Dengan luaran yang dihasilkan tersebut, ke depan komunitas Gubug Baca Cahaya Negeri bisa lebih berkembang dan maju.

\section{DAFTAR PUSTAKA}

Abdullah, T., \& Tantri, F. (2013). Manajemen Pemasaran (2nd ed.). Raja Grafindo Persada.

Badan Pusat Statistik Kabupaten Rembang. (2019). Kecamatan Kragan Dalam Angka 2019. BPS Kabupaten Rembang.

Kotler, P.T. and Armstrong, G. (2018). Principles of Marketing (17th ed.). Pearson.

Mahardika, E., dan Aji, G. G. (2018). Implementasi Komunikasi Pemasaran Digital Dalam Promosi Pariwisata (Studi Kasus Pada Kota Wisata Batu). Commercium, 2(2). pp: 5-.8

Prasetya, Y. H., \& Nurmahdi, A. (2018). Pengaruh Kegiatan Pemasaran Digital dan Perilaku Online Konsumen Pada Peningkatan Kesadaran Konsumen dan Dampaknya Terhadap Keputusan Pembelian Via Website. (No. Publikasi TM/51/16/054) [Tesis Magister, Universitas Mercu Buana]. Mercu Buana University Institutional Repository.

Pusat Penelitian Kebijakan Pendidikan dan Kebudayaan Balitbang Kemendikbud 2019, "Indeks Aktivitas Literasi Membaca 34 Provinsi".

UNESCO. (2019). International Literacy Day 2019: revisiting literacy and multilingualism, background paper. UNESCO. https://unesdoc.unesco.org/ark:/48223/pf0000370416 